\title{
Forecasting Long Term Jack up Vessel Demand for Offshore Wind
}

\author{
D. McMillan ${ }^{1} \&$ I. Dinwoodie ${ }^{2}$
}

${ }^{1}$ Institute for Energy \& Environment ${ }^{2}$ Centre for Doctoral Training in Wind Energy

Department of Electronics and Electrical Engineering

University of Strathclyde

Royal College Building

204 George Street

Glasgow, United Kingdom

Offshore wind deployment has greatly increased in the last decade. The number and size of installations have historically determined the requirement for jack up vessels, as installation was the only driver for heavy lift vessel requirement. The next phase of offshore wind development will change this situation, as jack up requirement for operations and maintenance will certainly increase as assets age, and in parallel larger sites continue to be installed and commissioned. The approach taken in this paper is to develop a long-term vessel demand model. This is achieved by a two stage process: firstly an installation jack up demand model is developed using UK offshore wind data for projects installed in the period 2003-2016. This model is utilized in tandem with an operations and maintenance jack up requirement model which is based on published reliability figures and failure duration data. The combined model captures the requirement for jack up vessels in the period 2012-2030. The paper concludes that demand for jack up vessels in UK waters will ramp up significantly in this decade, with an initial peak in 2014. A secondary peak around 2028 is highly dependent on assumptions regarding the trajectory of the turbine failure rate over time.

\section{INTRODUCTION}

Demand for jack up vessels in the offshore wind sector has been primarily driven by installation processes. Between 2002 and 2012 a total of 717 offshore wind turbines were installed in UK waters alone (RenewableUK, 2012). As shown in Fig. 1, demand was limited to 30 turbine installations per year or less in the period 2003-2007. However since then there has been a rapid increase in installations. In parallel to this installation demand, the requirement for jack up vessels for operations and maintenance $(\mathrm{O} \& \mathrm{M})$ will inevitably increase as the assets age. This new demand depends strongly on the number of heavy lift operations that are required per annum, which in turn depends on the failure rates of the turbines themselves. This paper moves towards a model for capturing jack up vessel requirement as the combined sum of installation work and O\&M.

\section{PREVIOUS WORK}

Research on O\&M modeling is plentiful in the literature. Obdam et al. (2007) and colleagues at ECN were the first to attempt to accurately model and measure O\&M costs for offshore wind. Bertling and colleagues (2010) and Byon et al. (2010) have produced research attempting to capture similar metrics. These works build on earlier applications of Markov chains to wind turbine reliability (Castro Sayas and Allan, 1996). Dinwoodie et al. (2012) performed similar analysis but with a strong focus on refining the access constraint model and performing model validation. The particular focus of this paper is long term demand for jack up vessels, which has not been addressed in depth in the literature until now.

\section{DATA}

The modelling in this paper focuses on turbines installed in UK waters only. The main reason for this is the availability of data. Databases containing the detailed information required to derive a jack up vessel demand model are not always publically available, however such data are available in the UK via trade body RenewableUK (2012). The method is equally applicable to any area: indeed future work must focus on quantifying European and global demand if adequate data becomes available. This is discussed further in the conclusions of the paper.

\section{MODELLING TURBINE INSTALLATION JACK UP VESSEL DEMAND}

Historic data are available for offshore wind installations in the UK. These fall into 3 broad categories: turbines in operation, turbines in construction and 
consented sites, and proposed sites in planning. The first modeling assumption in the paper is to ignore projects in planning (these would be commissioned post-2016). The reason for this is that there is currently a large amount of uncertainty regarding electricity market reform in the UK (DECC, 2012). The effect on private sector investors is to delay investment decisions until the outcomes of the reform are known. Due to this, projects in planning are not built into the installation demand model.

Fig. 1 shows the number of turbines installed by year in the period 2003-2012 (See Appendix 1 for data table), and the projected installations from 2013-2016 based on the assumptions previously discussed.

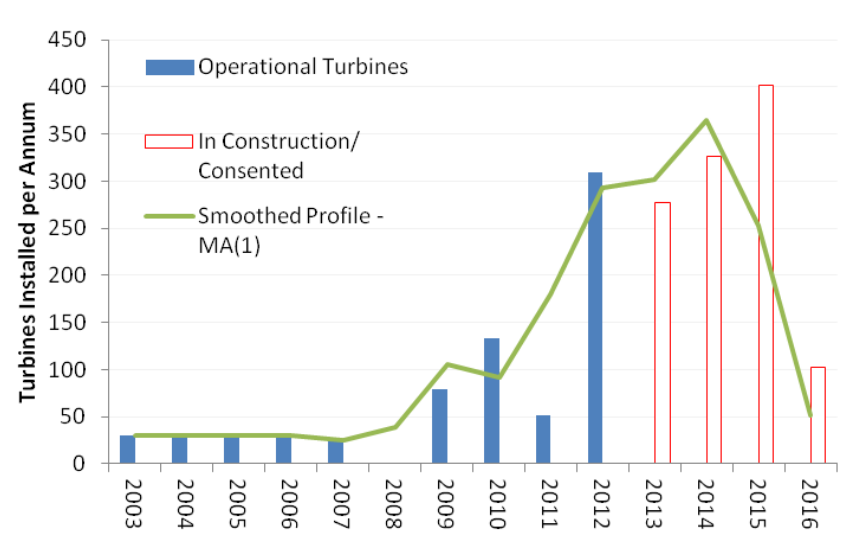

Figure 1. Offshore Wind Turbine UK Installation Profile.

Commissioning dates can be deceptive in the case of large offshore wind farms as construction is commonly spread over 2-3 years. To represent the impact of this fact on demand for jack up vessels, a moving average window (MA(1)) was applied to the data when the installed assets exceeded 50 turbines per annum. This has the effect of smoothing demand over the year previous to the commissioning year, and provides a more realistic installation profile.

In order to complete the installation demand model it is required to calculate the total amount of jack up vessel working hours required. To estimate the working hours involved in turbine installation, a set of installation rates derived from projects currently under construction is shown in Table 1.

Table 1. Estimated turbine installation rates offshore

\begin{tabular}{|c|c|c|c|c|}
\hline & $\begin{array}{l}\text { Number } \\
\text { turbines c }\end{array}$ & $\begin{array}{l}\text { Build } \\
\text { mplete* }\end{array}$ & $\begin{array}{c}\text { Build } \\
\text { duration* }\end{array}$ & RoInst* \\
\hline Project & \#WT & year & months & \#WT/montl \\
\hline Teeside $^{\alpha}$ & 27 & 2013 & 11 & 3.27 \\
\hline $\operatorname{Lincs}^{\beta}$ & 75 & 2013 & 11 & 9.09 \\
\hline Gwynt-y-Mor ${ }^{\gamma}$ & 160 & 2014 & 33 & 6.46 \\
\hline London Array I ${ }^{\delta}$ & 175 & 2013 & 19 & 12.28 \\
\hline
\end{tabular}

* Estimated

Table 1 sources:

${ }^{\alpha}$ (TeesideOffshoreWind, 2012)

$\beta$ (Lincs1, 2012, Lincs2, 2012)

$\gamma$ (Gwynt-y-Mor1, 2012, Gwynt-y-Mor2, 2012)

$\delta$ (LondonArray1, 2012, LondonArray2, 2012)
The rate of installation (RoInst) is calculated using Eq. (1) and Eq. (2), where $F_{\text {access }}$ is a factored increase of installation rate to correct for site inaccessibility during winter. For this study it was assumed that no installation work can be carried out in December, January and February. Therefore \#month$s_{\text {working }}=9$ and $F_{\text {access }}=1.333$. More sophisticated access constraint modeling is available in Dinwoodie et al (2012) and will be applied in future work.

$$
\text { RoInst }=\left[\frac{\# \text { turbines }}{\text { installation period months }}\right] \cdot \mathrm{F}_{\text {access }}
$$

$$
\mathrm{F}_{\text {access }}=\left[\frac{\# \text { months }_{\text {total }}}{\# \text { months }_{\text {working }}}\right]
$$

It is observed from Table 1 that RoInst shows a large amount of variation. This is due to multiple factors that are probably project-specific. To limit the scope of the study, the installation rate of London Array I was chosen (RoInst=12.28 turbines/month). Future studies will consider the underlying reasons for this and evaluate the role of a highly variable installation rate on jack up provision.

Having defined the RoInst, this can be used to calculate the demand for jack up vessel time (hours) in each year $\left(D(\text { inst })_{y r}\right)$ by applying Eq. (3):

$$
\mathrm{D}_{\text {inst }}=\left[\frac{\# \mathrm{WT}_{\mathrm{yr}}}{\text { RoInst }}\right] \cdot 720
$$

where $\# W T_{y r}$ is the number of turbines installed in each year derived from the characteristic shown in Fig. 1. The resultant modeled demand is plotted in Fig. 2.

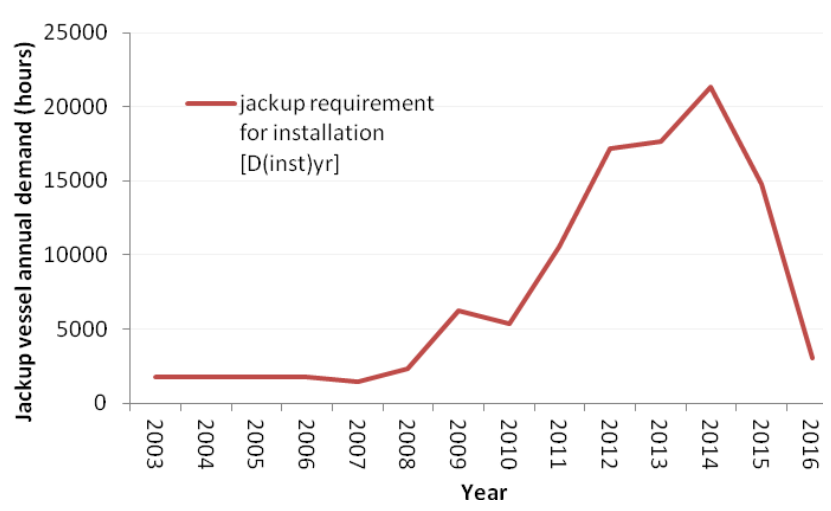

Figure 2. UK Modelled jack up vessel demand due to installation. 


\section{MODELLING TURBINE O\&M JACK UP VESSEL DEMAND}

Requirement for jack up vessels created by O\&M is driven by major component replacements. In order to calculate this, the three quantities required are: size of turbine population, failure rate, and duration of individual heavy lifting jobs. Size of population can be calculated by utilising the cumulative number of the installation profile calculated in Appendix 1 and assuming an asset life cycle of 20 years. The resulting modeled offshore turbine population is plotted out to a time horizon of 2030 in Fig. 3.

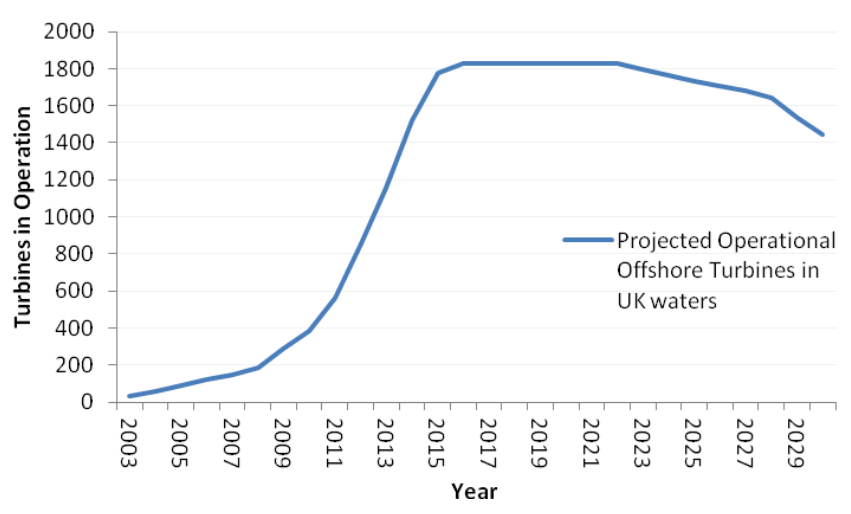

Figure 3. UK Modelled offshore wind turbine population by year

Some studies have broken turbine failure rates down so that the proportion of the failure rate attributable to major component replacements (requiring jack up) can be quantified. An example of such a study is that by Hendricks et al. (2010), where the authors define a 'major replacement' annual failure rate (referred to here as $\lambda_{1}$ ) of 0.1120 . It is assumed initially that the failure rate is constant over the life cycle, simplifying the calculation somewhat. Hendricks et al. ( 2010) also obtain illustrative figures for duration of major maintenance actions. In this paper a "major" action is assumed to require 70 hours of jack up vessel time (based on direct time to repair DTTR). These assumptions are relaxed in other work such as Dinwoodie et al. (2012) which considers failures in more detail.

While adequate for a first-pass analysis, the assumption of constant failure rate is almost certainly erroneous. Therefore a further model is introduced which includes the impact of ageing on the failure rate $\left(\lambda_{2}\right)$. The basis for this model is provided by Tavner and colleagues (2012) which provides some very insightful data in respect of wear out behavior of wind turbines. In this paper the failure rate is assumed to follow the failure pattern illustrated in (Tavner et al. 2012) with one major modification: early life "infant mortality" is not considered due to lack of data (the implications of these assumptions are discussed in the paper conclusions). A constant failure rate model is therefore assumed until year 10 of operation, after which the failure rate increases linearly as a function of operational year $\left(y r_{o p}\right)$ to a final value of $\lambda_{\text {final }}$ as shown in Eq. (4).

$$
\left\{\begin{array}{l}
\mathrm{yr}<=10, \quad \lambda_{2}=\lambda_{1} \\
10<\mathrm{yr}<=20, \quad \lambda_{2}=\left[\lambda_{\text {inal }}-\lambda_{1} / 10\right] y r_{o p}-10+\lambda_{1}
\end{array}\right\}
$$

In this study $\lambda_{\text {final }}=1.5 * \lambda_{1}$ : this represents an optimistic reliability scenario as Tavner et al. (2012) shows failure rates increasing by a factor of 4 or more in later life for onshore machines.

Applying a time-based failure rate to the data is more complex than the constant rate case. This is because the turbines move into the 'wear-out' region of the failure characteristic depending on the year they were installed (inst), relative to the current year of operation $(y r)$, resulting in a specific failure rate for each sub-population $\left(\lambda_{i n s t, y r}\right)$. Therefore a separate failure rate wear-out profile has to be built for turbines installed in successive years. This is of course simply a time-stepped version of Eq. (4).

The total frequency of failure for each year (frequr) is the sum of the product of each set of turbine failure rates at various stages of asset life $\left(\lambda_{\text {inst }}\right.$, $y r)$ and the number of turbines in the population which were installed in those years $\left(\# W T_{\text {inst, }}\right.$ yr $)$ - as shown in Eq. (5). From there, O\&M demand for jack up each year $\left(D(O \& M)_{y r}\right)$ is calculated directly via application of Eq. (6).

$$
\begin{aligned}
& \text { freq }_{\mathrm{yr}}=\sum_{\text {inst }=2003}^{2016} \lambda_{\text {inst, yr }} \cdot \# \mathrm{WT}_{\text {inst }, \mathrm{yr}} \\
& \text { D O \& } \mathrm{M}_{\mathrm{yr}}=\mathrm{DTTR} * \text { freq }_{\mathrm{yr}}
\end{aligned}
$$

Appendix 2 contains the resultant matrix of life histories developed for use in this paper, subject to the assumptions outlined above.

Fig. 4 shows the impact in terms of O\&M demand for jack up for the two failure rate assumptions. By modeling time-based increase in $\lambda$, it can be seen that the jack up demand continues to grow beyond 2016. If a constant rate had been assumed, one would conclude that demand would peak in 2016 and then continually reduce until the assets are retired. For modeling to support long term strategy and decision-making, Fig. 4 suggests that the constant failure rate assumptions currently underpinning much analysis in this field need to be re-visited in light of new information. 


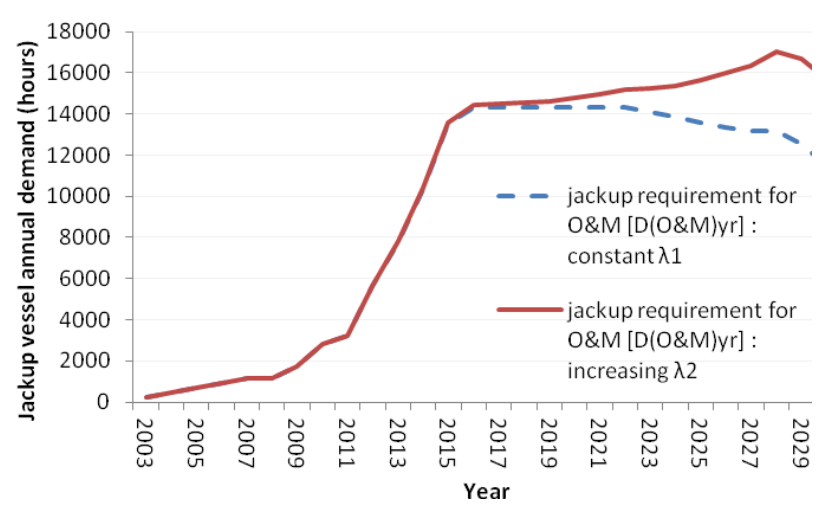

Figure 4. UK Modelled jack up vessel demand due to operation and maintenance

\section{RESULTS}

To calculate the total jack up vessel demand, the installation and O\&M demand are combined by applying Eq. (7).

$$
\text { D total }{ }_{\mathrm{yr}}=\mathrm{D} \mathrm{Inst}_{\mathrm{yr}}+\mathrm{D} \mathrm{O} \& \mathrm{M}_{\mathrm{yr}}
$$

The results are plotted in Fig. 5. The most immediate feature in Fig. 5 is the large demand peak in 2014. This is created primarily by the installation demand peaking in this period, although some of the earliest installations' O\&M requirements are also increasing by this time. The 2014 demand peak equates to a $40 \%$ increase on 2012 demand for jack up vessel working time.

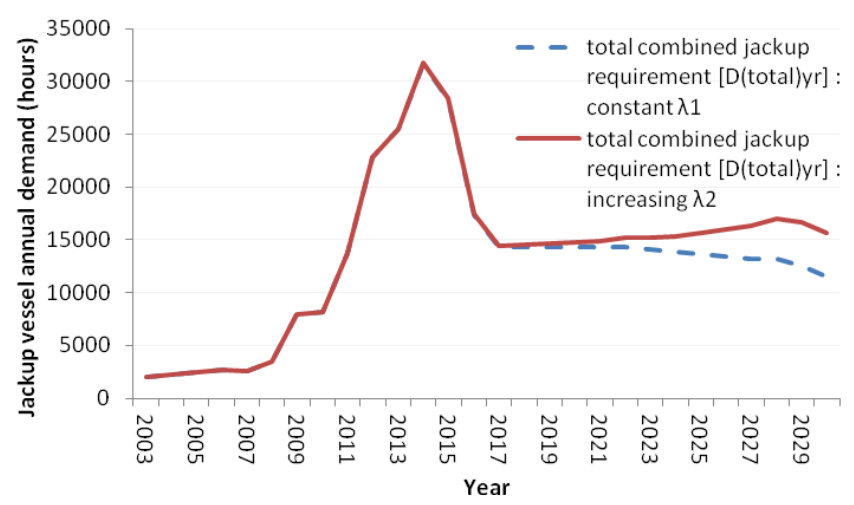

Figure 5. UK Modelled jackup vessel total demand

The second interesting feature is the impact of failure rate assumptions on demand in the late 2020's. Constant failure rate model assumptions result in demand reducing gradually in the period 2017-2030. By building ageing into the model, a second demand peak is observed around 2028. The possible economic implications of this are illustrated in Fig. 6 which is calculated by taking the difference between the 2 modelled demands and multiplying by a jack up charter rate of $\$ 38,000$ per day (Rigzone, 2012) while assuming a 7-hour shift.

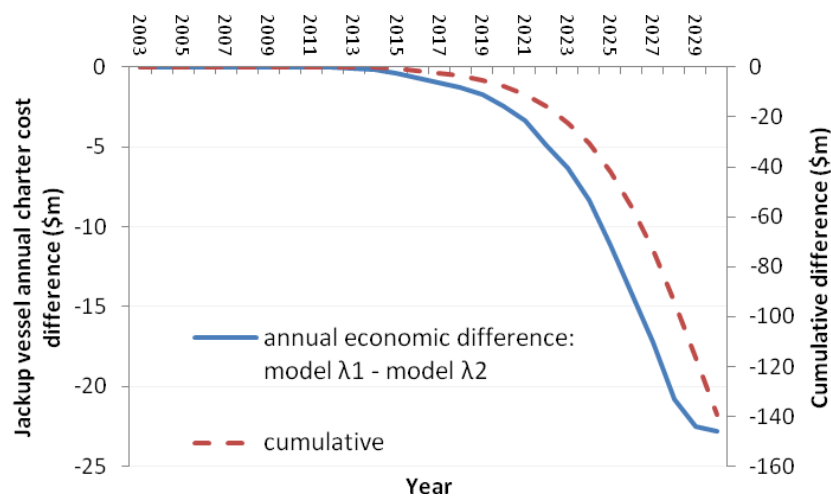

Figure 6. UK Jackup vessel cost implications of modeling assumptions

This result illustrates the need for more accurate reliability models of asset ageing behaviour for offshore wind turbines. This conclusion also strongly applies to models where life cycle cost is estimated. Future research effort should be directed to better quantifying ramp-up for failure rates (including rate of change of increase, and final magnitude of failure rates) in late-life cycle.

\section{MODEL ASSUMPTIONS \& UNCERTAINTY}

Due to time constraints, this problem has been simplified to provide an indicative first-pass analysis. The key assumptions made in the paper are discussed in this section along with associated uncertainty.

\subsection{UK Offshore Project Pipeline}

The biggest source of uncertainty when estimating future offshore wind installation demand is regulatory uncertainty. The pragmatic approach taken in this paper has been to exclude projects in the planning phase from the analysis until the outcome of electricity market reforms are known. The total number of turbines in planning is roughly 10,000 assets in UK waters alone (RenewableUK, 2013). It can be seen that this would represent a step-change in the magnitudes considered in this paper. Forecasting energy policy decision-making is difficult but this paper highlights the importance of market conditions and their impact. More work will be required to develop a decision-framework in which regulatory uncertainty can be evaluated and included in the model.

\subsection{EU and Global Demand}

Growth of offshore wind in the Baltic, non-UK regions of the North Sea and elsewhere is also highly subject to regulatory uncertainty. Beyond this important factor, variables underpinning the cost of generation will be influential in shaping future scenarios. 
Several authors have commented on and attempted to model the impacts of raw material prices on cost (McMillan, 2012) (Kaiser and Snyder, 2010). Again there is large uncertainty associated with attempting to derive a reliable estimate of commodity prices for a long time horizon. This uncertainty will be another factor which feeds through to final demand for jack up vessel services.

\subsection{Demand from North Sea Oil \&Gas}

Most existing jack up vessels were built to service the oil and gas industry. In some cases wind farm operators will be in direct competition with the oil and gas platform operators to procure jack up vessel services. How large this demand is and how it will change in the future is subject to uncertainty around investment e.g. in the North Sea. Timetables for decommissioning are also important, as is the appetite for investment and risk which will be driven primarily by oil prices. It follows that future work should combine demand models from both sectors.

\subsection{Failure rate \& DTTR}

This paper has leaned heavily on assumptions proposed in (Hendricks, 2010) and (Tavner, 2012). Offshore reliability metrics are uncertain simply because of the lack of assets in the water currently. Another aspect of uncertainty is the reliability of new wind turbine designs, knowledge of which is developing. As operational experience grows, this knowledge gap should be closed and better, more certain estimates of these quantities should be available in the near future.

\subsection{Rate of Installation \& Weather}

This paper has illustrated the wide range of installation rates experienced in the industry. Most of the uncertainty in rate of installation (RoInst) is caused by uncertainty around weather windows. Weather windows have been discussed in depth in (Dinwoodie and McMillan, 2012) and a deep discussion is beyond the scope of this paper. Project developers often carry weather risk in vessel contracts, therefore understanding of weather windows and wave regimes is crucial when pricing this risk. Future work will involve iterating this model further to better understand the play between weather regimes and RoInst.

\subsection{Vessel Supply}

The focus of this paper has been demand: however a comprehensive study of supply will be required in the next stages of this work.

\section{CONCLUSION}

This paper has described an original approach to quantify demand for jack up vessels based on both installation and ongoing O\&M requirement. To the knowledge of the author, this calculation has not been attempted in the literature to date. This calculation is hugely important because the cost of chartering a jack up vessel must be strongly dependent on demand for those vessels. All wind farm investors must therefore have an interest in quantifying demand for jack up vessels throughout the life cycle.

Several simplifying assumptions have been made in this paper to render the problem computationally tractable. Early life failures have been ignored on the basis that they occur during the period of a typical wind farm warranty (3-5 years). Furthermore, depending on the warranty contract, the wind farm operator may not incur costs associated with early life remedial work.

Other issues not covered by the modeling described above are decommissioning of offshore sites, and the possibility of repowering. These processes will undoubtedly affect the demand for jack up vessels, however so little is known about these processes for offshore wind that the author has omitted them from the current analysis. It would be interesting to take the modeling a step further by including demand associated with decommissioning as more information becomes available - this will be addressed in future research.

Similarly regarding the assumption of neglecting projects in planning, this is an assumption which should be revisited in light of the outcome of the UK government electricity market reform (DECC, 2012). A more complex reliability model could disaggregate failure processes enabling multiple failure rates for different components to be considered. Likewise, building non-UK EU demand, especially likely strong offshore wind growth in the Baltic and North Seas, would improve the model.

The ultimate aim of this research is to provide an input to a holistic model to estimate future jack up vessel cost by applying a demand and supply model. This is also the subject of ongoing work by the authors and colleagues.

\section{REFERENCES}

BESNARD, F. \& BERTLING, L. 2010. An Approach for Condition-Based Maintenance Optimization Applied to Wind Turbine Blades. IEEE Transactions on Sustainable Energy, 1, 77 - 83

BYON, E., NTAIMO, L. \& DING, Y. 2010. Optimal Maintenance Strategies for Wind Turbine Systems Under Stochastic Weather 
Conditions. IEEE Transactions on

Reliability, 59, 393 - 404

CASTRO SAYAS, F. \& ALLAN, R. N. 1996.

Generation availability assessment of wind

farms IEE Proceedings-Generation,

Transmission and Distribution, 143, 507 518

DECC 2012. Draft UK Energy Bill. UK: Department for Energy and Climate Change.

DINWOODIE, I. \& MCMILLAN, D. 2012. Analysis Of Offshore Wind Turbine Operation \& Maintenance Using A Novel Time Domain Meteo-ocean Modeling Approach. ASME Turbo Expo Copenhagen, Denmark.

DINWOODIE, I. A., MCMILLAN, D. \& QUAIL, F. 2012. Sensitivity of offshore wind turbine operation \& maintenance costs to key operational parameters. European Safety Reliability and Data Analysis Conference ESReDA 2012. Glasgow, UK.

GWYNT-Y-MOR1. 2012. Construction note

[Online]. Available:

http://www.rwe.com/web/cms/en/306614/rw e-innogy/sites/wind-offshore/underconstruction/gwynt-y-mr/summary/ [Accessed 28/09/12].

GWYNT-Y-MOR2. 2012. Construction vessel details [Online]. Available:

http://www.rwe.com/web/cms/mediablob/en/ 1531746/data/1203864/5/rweinnogy/sites/wind-offshore/underconstruction/gwynt-y-mr-home/latest-newsand-information/12-July-2012-Major-vesselcontract-maintains-schedule-for-Gwynt-yMr-turbine-installations.pdf [Accessed 28/09/12].

HENDRICKS, B. 2010. Reliawind: design for reliability. European Wind Energy Conference. Warsaw.

KAISER, M. \& SNYDER, B. 2010. Offshore Wind Energy Installation and Decommissioning Cost Estimation in the U.S. Outer Continental Shelf. US Bureau of Ocean Energy Management, Enforcement and Regulation.

LINCS1. 2012. Construction note [Online].

Available:

http://www.centrica.com/files/pdf/centrica_e nergy/lincs_construction_april_2012.pdf [Accessed 28/09/12].

LINCS2. 2012. Installation Note [Online].

Available:

http://www.offshorewind.biz/2012/09/19/tur bine-installation-starts-as-mt-hojgaardcompletes-work-on-lincs-wind-farm-uk/ [Accessed 28/09/12].

LONDONARRAY1. 2012. London Array 1 construction milestone [Online]. Available: http://www.londonarray.com/2012/08/30/ano ther-august-milestone-at-london-array/ [Accessed 28/09/12].

LONDONARRAY2. 2012. London Array 1 construction diary [Online]. Available: http://www.londonarray.com/news- developments/construction-

diary/album/72157625694854689/photo/593

6767186/construction-diary-51.html

[Accessed 28/09/12].

MCMILLAN, D. 2012. Wind farm capital cost regression model for accurate life cycle cost estimation. PMAPS. Istanbul.

OBDAM, B., RADEMAKERS, L., BRAAM, H. \& EECEN, P. 2007. Estimating Costs of Operation \& Maintenance for Offshore Wind Farms. European Offshore Wind Energy Conference. Berlin.

RENEWABLEUK. 2012. List of Operational Sites [Online]. Available: http://bwea.com/ukwed/operational.asp [Accessed 28/09/12 ].

RENEWABLEUK. 2013. Development Rounds UK Offshore Wind [Online]. Available: http://www.renewableuk.com/en/renewableenergy/wind-energy/offshorewind/development-rounds.cfm [Accessed].

RIGZONE. 2012. Offshore rig day rates- Jackup $M C<200^{\prime} W D$ [Online]. Available: http://www.rigzone.com/data/dayrates/ [Accessed 1/10/12].

TAVNER, P. J. 2012. Offshore Wind TurbinesReliability, Availability \& Maintenance, Institution of Engineering and Technology.

TEESIDEOFFSHOREWIND. 2012. Offshore wind farm project data [Online]. Available: http://www.teessideoffshorewindfarm.co.uk/ [Accessed 28/09/12 2012].

\section{APPENDIX 1}

UK Offshore Wind Project Data

\begin{tabular}{|c|c|c|c|}
\hline & $\begin{array}{l}\text { Number } \\
\text { turbines } \\
\text { installed }\end{array}$ & $\begin{array}{l}\text { Cumulative } \\
\text { number turbines } \\
\text { installed }\end{array}$ & $\begin{array}{l}\text { Jack up } \\
\text { installation } \\
\text { requirement }\end{array}$ \\
\hline Year & \#WT & \#WT & hours \\
\hline$\overline{2003}$ & 30 & 30 & 1759 \\
\hline 2004 & 30 & 60 & 1759 \\
\hline 2005 & 30 & 90 & 1759 \\
\hline 2006 & 30 & 120 & 1759 \\
\hline 2007 & 25 & 145 & 1466 \\
\hline 2008 & 0 & 145 & 0 \\
\hline 2009 & 79 & 224 & 4632 \\
\hline 2010 & 133 & 357 & 7798 \\
\hline 2011 & 51 & 408 & 2990 \\
\hline 2012 & 309 & 717 & 18116 \\
\hline 2013 & 277 & 994 & 16240 \\
\hline 2014 & 326 & 1320 & 19132 \\
\hline 2015 & 402 & 1722 & 23575 \\
\hline 2016 & 103 & 1825 & 6039 \\
\hline
\end{tabular}

Source: (RenewableUK, 2012) 


\section{APPENDIX 2}

Modelled Ageing Behaviour of Wind Farms

\begin{tabular}{|c|c|c|c|c|c|c|c|c|c|c|c|c|c|c|c|}
\hline & $\begin{array}{l}\text { inst }= \\
2003\end{array}$ & $\begin{array}{l}\text { inst= } \\
2004\end{array}$ & $\begin{array}{l}\text { inst }= \\
2005\end{array}$ & $\begin{array}{l}\text { inst= } \\
2006\end{array}$ & $\begin{array}{l}\text { inst= } \\
2007\end{array}$ & $\begin{array}{l}\text { inst }= \\
2008\end{array}$ & $\begin{array}{c}\lambda_{\text {inst, yr }} * \# \\
\text { inst }= \\
2009\end{array}$ & $\begin{array}{l}T_{\text {inst, yr }} \\
\text { inst= } \\
2010\end{array}$ & $\begin{array}{l}\text { inst= } \\
2011\end{array}$ & $\begin{array}{l}\text { inst }= \\
2012\end{array}$ & $\begin{array}{l}\text { inst= } \\
2013\end{array}$ & $\begin{array}{l}\text { inst }= \\
2014\end{array}$ & $\begin{array}{l}\text { inst }= \\
2015\end{array}$ & $\begin{array}{l}\text { inst= } \\
2016\end{array}$ & $\begin{array}{l}\text { Total number of } \\
\text { Jack up actions }\end{array}$ \\
\hline $\mathrm{yr}$ & & & & & & & & & & & & & & & freq $_{\mathrm{yr}}$ \\
\hline 2003 & 3.36 & 0.00 & 0.00 & 0.00 & 0.00 & 0.00 & 0.00 & 0.00 & 0.00 & 0.00 & 0.00 & 0.00 & 0.00 & 0.00 & 3.36 \\
\hline 2004 & 3.36 & 3.36 & 0.00 & 0.00 & 0.00 & 0.00 & 0.00 & 0.00 & 0.00 & 0.00 & 0.00 & 0.00 & 0.00 & 0.00 & 6.72 \\
\hline 2005 & 3.36 & 3.36 & 3.36 & 0.00 & 0.00 & 0.00 & 0.00 & 0.00 & 0.00 & 0.00 & 0.00 & 0.00 & 0.00 & 0.00 & 10.08 \\
\hline 2006 & 3.36 & 3.36 & 3.36 & 3.36 & 0.00 & 0.00 & 0.00 & 0.00 & 0.00 & 0.00 & 0.00 & 0.00 & 0.00 & 0.00 & 13.44 \\
\hline 2007 & 3.36 & 3.36 & 3.36 & 3.36 & 2.80 & 0.00 & 0.00 & 0.00 & 0.00 & 0.00 & 0.00 & 0.00 & 0.00 & 0.00 & 16.24 \\
\hline 2008 & 3.36 & 3.36 & 3.36 & 3.36 & 2.80 & 0.00 & 0.00 & 0.00 & 0.00 & 0.00 & 0.00 & 0.00 & 0.00 & 0.00 & 16.24 \\
\hline 2009 & 3.36 & 3.36 & 3.36 & 3.36 & 2.80 & 0.00 & 8.85 & 0.00 & 0.00 & 0.00 & 0.00 & 0.00 & 0.00 & 0.00 & 25.09 \\
\hline 2010 & 3.36 & 3.36 & 3.36 & 3.36 & 2.80 & 0.00 & 8.85 & 14.90 & 0.00 & 0.00 & 0.00 & 0.00 & 0.00 & 0.00 & 39.98 \\
\hline 2011 & 3.36 & 3.36 & 3.36 & 3.36 & 2.80 & 0.00 & 8.85 & 14.90 & 5.71 & 0.00 & 0.00 & 0.00 & 0.00 & 0.00 & 45.70 \\
\hline 2012 & 3.36 & 3.36 & 3.36 & 3.36 & 2.80 & 0.00 & 8.85 & 14.90 & 5.71 & 34.61 & 0.00 & 0.00 & 0.00 & 0.00 & 80.30 \\
\hline 2013 & 3.53 & 3.36 & 3.36 & 3.36 & 2.80 & 0.00 & 8.85 & 14.90 & 5.71 & 34.61 & 31.02 & 0.00 & 0.00 & 0.00 & 111.50 \\
\hline 2014 & 3.70 & 3.53 & 3.36 & 3.36 & 2.80 & 0.00 & 8.85 & 14.90 & 5.71 & 34.61 & 31.02 & 36.55 & 0.00 & 0.00 & 148.38 \\
\hline 2015 & 3.86 & 3.70 & 3.53 & 3.36 & 2.80 & 0.00 & 8.85 & 14.90 & 5.71 & 34.61 & 31.02 & 36.55 & 45.04 & 0.00 & 193.92 \\
\hline 2016 & 4.03 & 3.86 & 3.70 & 3.53 & 2.80 & 0.00 & 8.85 & 14.90 & 5.71 & 34.61 & 31.02 & 36.55 & 45.04 & 11.54 & 206.13 \\
\hline 2017 & 4.20 & 4.03 & 3.86 & 3.70 & 2.94 & 0.00 & 8.85 & 14.90 & 5.71 & 34.61 & 31.02 & 36.55 & 45.04 & 11.54 & 206.94 \\
\hline 2018 & 4.37 & 4.20 & 4.03 & 3.86 & 3.08 & 0.00 & 8.85 & 14.90 & 5.71 & 34.61 & 31.02 & 36.55 & 45.04 & 11.54 & 207.75 \\
\hline 2019 & 4.54 & 4.37 & 4.20 & 4.03 & 3.22 & 0.00 & 9.29 & 14.90 & 5.71 & 34.61 & 31.02 & 36.55 & 45.04 & 11.54 & 209.01 \\
\hline 2020 & 4.70 & 4.54 & 4.37 & 4.20 & 3.36 & 0.00 & 9.73 & 15.64 & 5.71 & 34.61 & 31.02 & 36.55 & 45.04 & 11.54 & 211.01 \\
\hline 2021 & 4.87 & 4.70 & 4.54 & 4.37 & 3.50 & 0.00 & 10.18 & 16.39 & 6.00 & 34.61 & 31.02 & 36.55 & 45.04 & 11.54 & 213.29 \\
\hline 2022 & 5.04 & 4.87 & 4.70 & 4.54 & 3.64 & 0.00 & 10.62 & 17.13 & 6.28 & 36.34 & 31.02 & 36.55 & 45.04 & 11.54 & 217.31 \\
\hline 2023 & 0.00 & 5.04 & 4.87 & 4.70 & 3.78 & 0.00 & 11.06 & 17.88 & 6.57 & 38.07 & 32.58 & 36.55 & 45.04 & 11.54 & 217.67 \\
\hline 2024 & 0.00 & 0.00 & 5.04 & 4.87 & 3.92 & 0.00 & 11.50 & 18.62 & 6.85 & 39.80 & 34.13 & 38.38 & 45.04 & 11.54 & 219.68 \\
\hline 2025 & 0.00 & 0.00 & 0.00 & 5.04 & 4.06 & 0.00 & 11.94 & 19.36 & 7.14 & 41.53 & 35.68 & 40.20 & 47.29 & 11.54 & 223.79 \\
\hline 2026 & 0.00 & 0.00 & 0.00 & 0.00 & 4.20 & 0.00 & 12.39 & 20.11 & 7.43 & 43.26 & 37.23 & 42.03 & 49.54 & 12.11 & 228.30 \\
\hline 2027 & 0.00 & 0.00 & 0.00 & 0.00 & 0.00 & 0.00 & 12.83 & 20.85 & 7.71 & 44.99 & 38.78 & 43.86 & 51.79 & 12.69 & 233.51 \\
\hline 2028 & 0.00 & 0.00 & 0.00 & 0.00 & 0.00 & 0.00 & 13.27 & 21.60 & 8.00 & 46.72 & 40.33 & 45.69 & 54.04 & 13.27 & 242.92 \\
\hline 2029 & 0.00 & 0.00 & 0.00 & 0.00 & 0.00 & 0.00 & 0.00 & 22.34 & 8.28 & 48.45 & 41.88 & 47.51 & 56.30 & 13.84 & 238.61 \\
\hline 2030 & 0.00 & 0.00 & 0.00 & 0.00 & 0.00 & 0.00 & 0.00 & 0.00 & 8.57 & 50.18 & 43.43 & 49.34 & 58.55 & 14.42 & 224.49 \\
\hline
\end{tabular}

